\title{
Chronobiology of Plasmodium chabaudi chabaudi: ANALYSIS OF HOURLY RECORDED TOTAL AND DIFFERENTIAL PARASITAEMIA DURING A SCHIZOGONIC CYCLE
}

\author{
CHIMANUKA B.*, ****, FRANÇOIS G.**, TIMPERMAN G.**, VANDEN DRIESSCHE T.*** \& PLAIZIER-VERCAMMEN J.*
}

\begin{abstract}
Summary :
Detailed total and differential parasitaemia curves of asexual Plasmodium chabaudi chabaudi erythrocytic stages were recorded and analysed. Female, inbred, CBA/Ca mice were infected with the virulent IP-PCl strain after in vitro synchronization of the parasites. Thin blood smears were made on an hourly basis, and the total and differential parasitaemia of ring forms, trophozoites and schizonts were counted after Giemsa staining. These curves reveal information that remains hidden when less detailed curves are examined: the duration and periodicity of the schizogonic cycle, the existence of a plateau, indications of a schizont withdrawal from the peripheral blood, the timing of the rise of the parasitaemia at each schizogony, and the invasion rate of the merozoites. In the perspective of developing a rational and efficient strategy for chronotherapy of malaria, such information should be taken into account.
\end{abstract}

KEY WORDS : malaria, Plasmodium chabaudi chabaudi, chronobiology, parasitaemia curves, schizogonic cycle.
Résumé : Chronobiologie de Plasmodium ChabaUdi CHABaUd : ANALYSE DES COURBES HORAIRES DES PARASITÉMIES TOTALES ET DIFFERENTIELLES PENDANT UN CYCLE SCHIZOGONIQUE

Des courbes détaillées de parasitémie totale et différentielle des stades érythrocytaires asexués de Plasmodium chabaudi chabaudi ont été établies et analysées. Des souris femelles CBA/Ca ont été infectées avec la souche virulente IP-PCI après une synchronisation in vitro. Des frottis sanguins ont été faits chaque heure. Les parasitémies totales et différentielles ont été évaluées après coloration au Giemsa et comptage des formes en anneaux, des trophozoïtes et des schizontes. Les courbes obtenues ont révélé des détails qui seraient restés cachés si l'intervalle entre les échantillonages avait été plus long, notamment la durée et la périodicité du cycle schizogonique, la présence d'un plateau, des indications sur une disparition des schizontes du sang périphérique, le moment de la montée de la parasitémie après la schizogonie et le taux d'invasion des mérozoites. En vue du développement d'une stratégie rationelle et efficace pour la chronothérapie de la malaria, les informations révélées par ce type de courbes devraient être prises en considération.

MOTS CLÉS : malaria, Plasmodium chabaudi chabaudi, chronobiologie, courbes de parasitémie, cycle schizogonique.

chabaudi in their rodent host based upon hourly made thin blood smears. P. chabaudi chabaudi is an interesting experimental model (Landau et al., 1993) and shares a number of biological features with $P$. falciparum (Jarra \& Brown, 1985; Gilks et al., 1990). Besides, P. chabaudi chabaudi infections are synchronous, with a period of 24 hours, and depend on the circadian rhythm of the host (Cambie et al., 1990; Landau et al., 1990, 1991).

\section{MATERIALS AND METHODS}

MicE

\footnotetext{
-Faculteit Geneeskunde en Farmacie, Vrije Universiteit Brussel, Laarbeeklaan 103, B-1090 Jette, Belgium.

" Prins Leopold Instituut voor Tropische Geneeskunde, Nationalestraat 155, B-2000 Antwerpen, Belgium.

-.. Département de Biologie Moléculaire, Université Libre de Bruxelles, rue des Chevaux, 67, B-1640 Rhôde Saint-Genèse.

.... Laboratoire d'Entomologie et Parasitologie Médicale, Centre de Recherche en Sciences Naturelles, Lwiro, D.S. Bukavu, Kivu, Congo. Correspondence : B. Chimanuka.

Phone : (32) 24774598 - Fax: (32) 24774113.
}

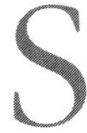
ix-week-old, female, inbred, pathogen-free, $\mathrm{CBA} / \mathrm{Ca}$ mice (Kingman, England) were kept in plastic translucent cages at $21^{\circ} \mathrm{C}$ and $50 \%$ relative air humidity. Their photoperiodic rhythm was set by a regimen of 12 hours light ( $13 \mathrm{~h} 00$ $01 \mathrm{~h} \mathrm{00)/12} \mathrm{hours} \mathrm{dark} \mathrm{(01} \mathrm{h} \mathrm{00-13} \mathrm{h} \mathrm{00).} \mathrm{The} \mathrm{mice}$ were handled conform with national and international legislation and guidelines. 


\section{PARASITE AND INFECTION}

The virulent IP-PC1 strain of P. chabaudi chabaudi was inoculated into a $\mathrm{CBA} / \mathrm{Ca}$ mouse. When a parasitaemia of $30-50 \%$ was reached and late schizonts predominantly occurred, $1 \mathrm{ml}$ of blood was suspended in RPMI 1640 (GibcoBRL) supplemented with $10 \%$ foetal calf serum (FCS; GibcoBRL), and centrifuged. The recovered erythrocytes containing mature schizonts were resuspended in the same medium and incubated at $37^{\circ} \mathrm{C}$ for 30 minutes to liberate the merozoites. After centrifugation, the supernatant containing the merozoites was centrifuged again, and the brownish pellet was resuspended in $250 \mu \mathrm{l}$ of PBS ( $\mathrm{pH}$ 7.3) and immediately i.v. injected into another mouse at $10 \mathrm{~h} 00$. When its parasitaemia had reached a level of about $10 \%$ (ring forms), $10^{6}$ infected red blood cells in sterile Alsever medium ( $\mathrm{pH}$ 6.2) were i.v. injected into 4 receptor mice at $11 \mathrm{~h} 00$. The experiment was started when the parasitaemia of these mice reached a level of 5-10\% and about $30 \%$, respectively.

\section{TOTAL AND DIFFERENTIAL PARASITAEMIA}

After Giemsa staining of thin blood smears, the total parasitaemia (number of infected red blood cells expressed as a percentage of the total number of red blood cells) and the differential parasitaemia (numbers of ring forms, trophozoites, and schizonts, expressed as percentages of the total number of infected red blood cells) were determined. Ring forms were defined as the stages developing between the attachment of merozoites to the erythrocytes and the disappearance of the ring specific vacuole, while trophozoites did not display such a vacuole and their cytoplasm was larger than the one of the ring shaped parasites. Schizonts occupied most of the host erythrocyte cytoplasm, with a very dense and/or dividing nucleus. For each smear a minimum of 100 infected red blood cells was counted.

\section{RESULTS}

\section{TOTAL PARASITAEMIA CURVES}

he detailed time course of the total parasitaemia of mice with an initial parasitaemia of - $5-10 \%$ is given in figure $1 a$. By the end of the dark period a plateau level with a constant parasitaemia of ca. $12.5 \%$ was reached, which lasted the full length of the light period plus 2-3 hours of the dark period. At the end of the plateau the parasitaemia showed a distinct decrease with a minimum level roughly corresponding with the middle of the second dark period. Then it rose sharply and reached a new plateau level with a parasitaemia of ca. $37.5 \%$.
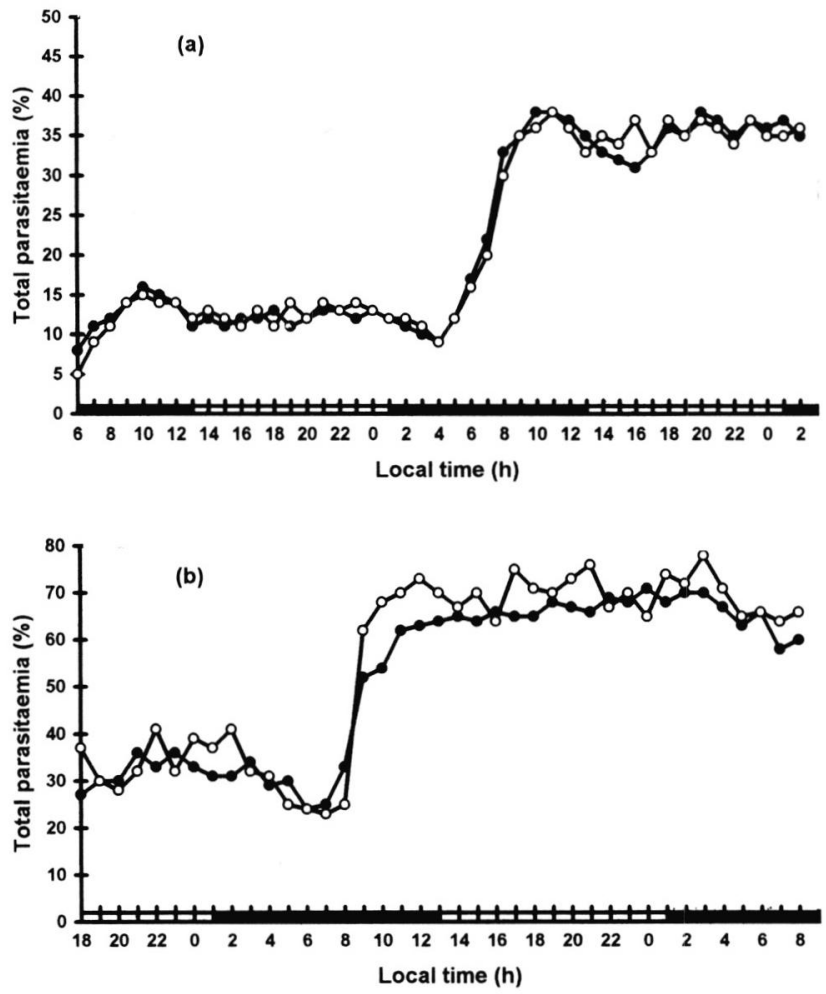

Fig. 1. - Time course of total parasitaemia of Plasmodium chabaudi chabaudi (IP-PC1) infected CBA/Ca mice ( $\bullet$ and O), based upon the evaluation of hourly made thin blood smears. Photoperiodic rhythm of the mice set by a cycle of $12 \mathrm{~h}$ dark $(01 \mathrm{~h} 00-13 \mathrm{~h} \mathrm{00)/12} \mathrm{h} \mathrm{light}$ (13 h 00-01 h 00). a) Initial parasitaemia 5-10\%; b) Initial parasitaemia ca. $30 \%$.

These observations correspond well with those made on the infected mice displaying a higher initial parasitaemia (ca. $30 \%$ ) (Fig. 1b). Furthermore, these results are in agreement with those obtained in a series of analogous experiments carried out with infected female outbred OF1 mice (B. Chimanuka, unpubl. obs.). No anaemia was noticed after the schizogony at $30 \%$. The parasitaemia reached a plateau of $60-70 \%$ at the end of which the crisis occurred.

\section{INVASION RATES}

Invasion rates were obtained by dividing the values of two consecutive plateau levels. Figure $1 a$ yields a rate of about 3 , while a value of about 2 is deduced from figure $1 b$. In previous experiments (B. Chimanuka, unpubl. obs.) we obtained higher invasion rates of 10 and 8 , when initial parasitaemias were 0.1 and $1 \%$, respectively. The correlation between initial parasitaemia and invasion rate is clearly negative $(r=-0.87)$.

\section{DiFFERENTIAL PARASITAEMIA CURVES}

The development of ring forms, trophozoites, and schizonts, corresponding with the total parasitaemia curves of figure $1 a$, is shown in figure 2. Gametocytes 
were not observed throughout this experiment. The duration of the developmental stages was estimated at 12 hours for the rings, 8 hours for the trophozoites, and $4 \mathrm{~h}$ for the schizonts.

The proportion of ring forms rose sharply at the beginning of the experiment and remained almost constant at a level of about $95 \%$ until the end of the first light period. Then it decreased to reach a minimum level of $10 \%$ in the middle of the second dark period. The proportion of trophozoites on the other hand was on the decrease when the observations begun and stayed at a very low level $(<5 \%)$ during the light period. Then it increased to reach a peak level of about $75 \%$ of the total number of parasites by the middle of the second dark period. The schizont curve showed peaks at $25-30 \%$ and $40-45 \%$, each of them occurring $7-8$ hours after the onset of the dark periods, i.e. 2-3 hours after the appearance of the trophozoite peaks. In between, the proportion of schizonts did not exceed $5 \%$ of the total number of infected erythrocytes. The differential distribution curves showed a cyclic pattern, as illustrated by the observations made after the first 24 hours of the experiment.

\section{DISCUSSION}

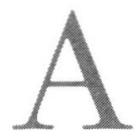

nalysis of the total parasitaemia curves (Fig. 1) reveals the duration and the periodicity of the schizogonic cycle, the existence of a plateau, indications of schizont withdrawal from the peripheral blood, the timing of the rise of the parasitaemia, and the invasion rate of the merozoites. The initial increase of the total parasitaemia (Fig. 1a) during the second half of the dark period corresponds with the appearance of ring forms (Fig. 2) after the release of merozoites by mature schizonts. When the total parasi- taemia reaches a plateau, ring forms are predominant and account for at least $95 \%$ of the infected erythrocytes (Fig. 2). Other authors (Hommel et al., 1982; Boyle et al., 1983; Cox et al., 1987; Gilks et al., 1990) mentioned only part of these possibilities or used the curves for different purposes. The position of the parasitaemia drop at the end of each plateau phase perfectly coincides with the rising slope of the schizont peak. Similar drops were observed with $P$. chabaudi adami by Gautret (1993). This phenomenon has been explained by the disappearance of schizonts from the peripheral blood and their sequestration in the inner organs, mainly the liver and the spleen (Cox et al., 1987; Gilks et al., 1990). This peripheral withdrawal was estimated at $8-10 \%$ of the preceeding plateau level.

The apparent discrepancy observed between the duration of the presence of ring forms in this paper (12 $\mathrm{h}$ ) and in other reports (6 h) (Cambie et al., 1990; Caillard et al., 1992; Gautret et al., 1995) is due to the fact that our ring forms coincide with the combined ring and young trophozoite forms described by the mentioned authors.

Schizonts of other species such as P. falciparum and $P$. berghei are sequestered in the cerebral capillaries and are not frequently seen in the peripheral blood (Kwiatkowski \& Greenwood, 1989; Lambert \& Grau, 1989). This explains why severe P. falciparum malaria attacks can even occur with little or no evidence of parasites in the examined blood films (Carme et al., 1989). It means that a more pronounced drop in the total parasitaemia curve can be expected in the case of $P$. falciparum. In principle, this phenomenon could be developed as a diagnostic parameter for the onset of cerebral $P$. falciparum malaria, as sequestration is the key initiating event for this pathology (Warrell, 1987).

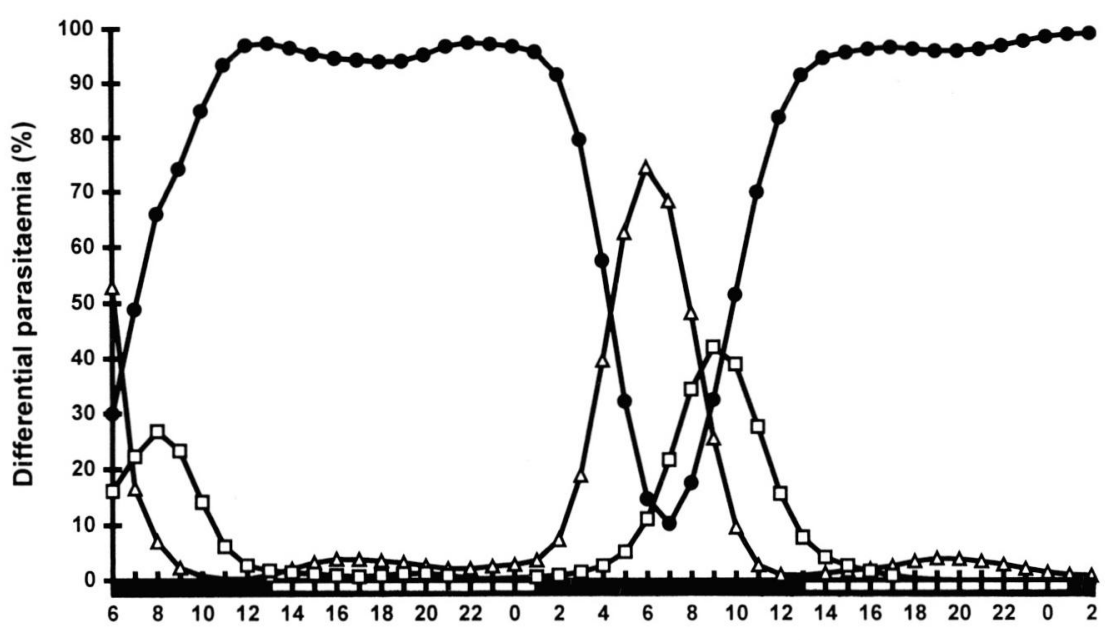

Local time $(h)$
Fig. 2. - Time course of differential parasitaemia of Plasmodium chabaudi chabaudi (IP-PC1) infected CBA/Ca mice, based upon the evaluation of hourly made thin blood smears. Data corresponding with the total parasitaemia of figure $1 a$. Proportions of ring forms $(\bullet)$, trophozoites $(\Delta)$, and schizonts ( $\square$ ) expressed as percentages of the total number of infected erythrocytes. Photoperiodic rhythm of the mice set by a cycle of 12 h dark (01 h 00-13 h 00)/12 h light (13 h 00-01 h 00). 
The invasion rate with a value of 2 , deduced from figure $1 b$ ), corresponds with the one given by others (Boyle et al., 1983). However, invasion rates of about 10 and 8 obtained in other experiments (B. Chimanuka, unpubl. obs.) correspond with the mean number of merozoites produced per mature schizont (Landau, 1965). The negative correlation between invasion rate and initial parasitaemia could be explained by the fact that at high parasitaemia levels less erythrocytes are available for invasion because many of them are lysed at each schizogony, immune reactions are more pronounced (Jayawardena, 1981), multiple invasion of red blood cells occurs, and free merozoites could aggregate both within themselves and with pigment and membranes, as has been shown for P. falciparum (Vernot \& Wasserman, 1990).

The timing of the administration of antimalarial drugs to the target parasite stage has been proposed by many authors (Yayon et al., 1983; Cambie et al., 1991; Caillard et al., 1992; Landau et al., 1992). In such a strategy, the parasitaemia curves presented in this report could become an important tool.

\section{ACKNOWLEDGEMENTS}

W e appreciate the participation of D. Hendrix, P. Desai, T. Scorza, E. C. Chimfwembe, T. Steenackers, and J. Lisgarten in experiments and discussions, and thank R. Wynants and M.-Th. Delobel for taking care of the mice. We thank Prof. R. Hamers for initiating this work and Prof. I. Landau for her critical comments. Financial support from the UNDP/World Bank/WHO Special Programme for Research and Training in Tropical Diseases (TDR) is gratefully acknowledged. B.C. thanks the Belgian Cooperation Administration (ABOS/AGCD) for his research grant.

\section{REFERENCES}

Boyle D.B., March J.C., Newbold C.I. \& Brown K.N. Parasite polypeptides lost during schizogony and erythrocyte invasion by the malaria parasites, Plasmodium chabaudi and Plasmodium knowlesi. Molecular and Biochemical Parasitology, 1983, 7, 9-18.

Caillard V., Beauté-Lafitte A., Chabaud A.G. \& Landau I. Plasmodium vinckei petteri: identification of the stages sensitive to arteether. Experimental Parasitology, 1992, 75, 449-456.

Cambie G., Landau I. \& Chabaud A.G. Niches horaires des trois espèces de Plasmodies coexistant chez un rongeur de Centrafrique. Comptes Rendus de l'Académie de Sciences de Paris, 1990, 310 Série III, 183-188.
Cambie G., Caillard V., Beauté-Lafitte A., Ginsburg H., ChaBAUD A. \& LANDAU I. Chronotherapy of malaria: identification of drug-sensitive stage of parasite and timing of drug delivery for improved therapy. Annales de Parasitologie Humaine et Comparée, 1991, 66, 14-21.

Carme B., Yombi B. \& Plassart H. (1989). L'accès palustre : un diagnostic difficile en région de forte endémicité à Plasmodium falciparum. Bulletin de la Société de Pathologie Exotique, 1989, 82, 578-580.

Cox J., Semoff S. \& Hommel M. Plasmodium chabaudi: a rodent malaria model for in vivo and in vitro cytoadhrence of malaria parasites in the absence of knobs. Parasite Immunology, 1987, 9, 543-561.

Gautret P. Les Plasmodium de Muridés de la République du Congo: étude de la périodicité et du rythme des cycles érythrocytaires. Études Approfondies Interactions Hôtes Parasites. Université Paris XII, Val-de-Marne, 1993.

Gautret P., Deharo E., Tahar R., Chabaud A.G. \& Landau I. The adjustment of the schizogonic cycle of Plasmodium chabaudi chabaudi in the blood to the circadian rhythm of the host. Parasite, 1995, 2, 69-74.

Gil.ks C.F., Walliker D. \& Newbold C.I. Relationships between sequestration, antigenic variation and chronic parasitism in Plasmodium chabaudi chabaudi - a rodent malaria model. Parasite Immunology, 1990, 12, 45-64.

Hommel M., David P.H., Guillotte M. \& Pereira Da Silva L. Protection against Plasmodium chabaudi malaria. I. Vaccination of mice with merozoites and Freund's adjuvants. Annales d'Immunologie, 1982, 133 C, 57-67.

JARRA W. \& Brown K.N. Protective immunity to malaria: studies with cloned lines of Plasmodium chabaudi and $P$. berghei in $\mathrm{CBA} / \mathrm{Ca}$ mice. I. The effectiveness and interand intra-species specificity of immunity induced by infection. Parasite Immunology, 1985, 7, 595-606.

JAYAWARDENA A.N. Immune responses in malaria, in: Mansfield J.M. (ed.), Parasitic Diseases, Vol. 1, The Immunology. Marcel Dekker, New York, 1981, 85-125.

KwIATKOWSKI D. \& Greenwood B.M. Why is malaria fever periodic? A hypothesis. Parasitology Today, 1989, 5, 264-266.

Lambert P.-H. \& Grau G.E. Cerebral malaria, in: McAdam K.P.W.J. (ed.), New Strategies in Parasitology. Churchill Livingstone, Edinburgh, 1989, 51-71.

LANDAu I. Description de Plasmodium chabaudi n. sp., parasite de rongeurs africains. Comptes Rendus de l'Académie des Sciences de Paris, 1965, 260, 3758-3761.

Landau I., Cambie G. \& Chabaud A.G. Biology of Plasmodium merozoites with special reference to the chemoresistance of Plasmodium falciparum. Annales de Parasitologie Humaine et Comparée, 1990, 65, 101-103.

Landau I., Chabaud A., Cambie G. \& Ginsburg H. Chronotherapy of malaria: an approach to malaria chemotherapy. Parasitology Today, 1991, 7, 350-352.

Landau I., Lepers J.-P., Ringwald P., Rabarison P., Ginsburg H. \& Chabaud A. Chronotherapy of malaria: improved efficacy of timed chloroquine treatment of patients with Plasmodium falciparum infections. Transactions of the Royal Society of Tropical Medicine and Hygiene, 1992, 86, 374375. 
Landau I., Caillard V., Beauté-Lafitte A. \& Chabaud A. Chronobiology and chronotherapy of malaria: investigations with murine malaria models. Parassitologia, 1993, 35 (Suppl.), 55-57.

Vernot J.P. \& Wasserman M. Plasmodium falciparum: increased and multiple invasion during short periods of time. Journal of Protozoology, 1990, 37, 47-49.

WARrell D.A. Pathophysiology of severe falciparum malaria in man. Parasitology, 1987, 94, S53-S76.

Yayon A., VAnde WAa J.A., Yayon M., Geary T.G. \& Jensen J.B. Stage-dependent effects of chloroquine on Plasmodium falciparum in vitro. Journal of Protozoology, 1983, 30, 642-647.

Reçu le 21 avril 1997 Accepté le 24 juillet 1997 